\title{
ANALISIS TEKNOEKONOMI ALAT PENYEMBELIHAN AYAM UNTUK MENDUKUNG IMPLEMENTASI SISTEM JAMINAN HALAL
}

\section{TECHNO ECONOMIC ANALYSIS OF CHICKEN SLAUGHTERING EQUIPMENT FOR SUPPORTING HALAL ASSURANCE SYSTEM IMPLEMENTATION}

\author{
Sucipto Sucipto $\left.^{1,2}\right)^{*}$, Riska Indra Wardani ${ }^{1)}$, Muhammad Arif Kamal ${ }^{1,2)}$, Danang Triagus Setiyawan ${ }^{1,2)}$ \\ ${ }^{1)}$ Program Studi Teknologi Industri Pertanian, Universitas Brawijaya, \\ Gedung Fakultas Teknologi Pertanian Lantai 5, Jl. Veteran Malang, 65145. \\ Email: ciptotip@ub.ac.id \\ ${ }^{2)}$ Halal-Qualified Industry Development (Hal-Q ID), Universitas Brawijaya, \\ Gedung Fakultas Teknologi Pertanian Lantai 5, J1. Veteran Malang, 65145.
}

Makalah: Diterima 18 Maret 2019; Diperbaiki 23 Desember 2019; Disetujui 10 Januari 2020

\begin{abstract}
Halal certified animal slaughtering is urgent to implement and develop. The halal of chicken meat is determined by halal control point $(\mathrm{HCP})$ in the production process, production capacity, and selection of slaughtering equipment. Many chicken slaughterings have not been halal certified because their production equipments do not yet support the application of the Halal Assurance System (HAS). The study aimed to analyse HCP in the production process, the techno-economic analysis of small and medium chicken slaughtering to support HAS implementation. The results showed that with the technical aspect of the medium-scale chicken meat production had HCP at the stage of hanging, stunning, and slaughtering, while the small-scale production of chicken meat had HCP at the slaughtering stage and the collection of slaughtered until perfectly death chickens. Economically, medium-scale slaughtering simulation results of capacity increased to 3,000 chickens per day can use shackle conveyor; thus, reducing Cost of Goods Manufactured (COGM) becomes IDR 22,029 and selling price become IDR 28,638 per chicken. Besides that, small scale slaughtering with a simulated capacity increase of 300 chickens per day with the addition of simple shackle to overcome HCP collection of post-slaughtering. This condition caused the COGM to be IDR 22,016 and the selling price is IDR 28,621 per chicken. In general, the choice of chicken slaughtering equipment according to production capacity will help the implementation of HAS to obtain a competitive product efficiently.
\end{abstract}

Keywords: slaughtering, equipment, chicken, capacity, HCP, Halal Assurance System

\begin{abstract}
ABSTRAK
Penyembelihan hewan bersertifikasi halal penting untuk diterapkan dan dikembangkan. Kehalalan daging ayam ditentukan oleh aspek Halal Control Point (HCP) selama proses produksi, kapasitas produksi, dan seleksi alat penyembelihan. Banyak penyembelihan ayam belum tersertifikasi halal karena peralatan produksinya belum mendukung penerapan Sistem Jaminan Halal (SJH). Penelitian ini bertujuan untuk menganalisis HCP proses produksi, kelayakan teknis dan ekonomi penyembelihan ayam skala menengah dan kecil untuk mendukung implementasi SJH. Penelitian menggunakan metode analisis diskriptif, baik kualitatif dan kuantitatif. Hasil riset menunjukkan secara teknis produksi daging ayam skala menengah memiliki HCP pada tahap penggantungan, stunning, dan penyembelihan, sedang produksi daging ayam skala kecil memiliki HCP pada tahap penyembelihan dan pengumpulan ayam tersembelih hingga mati sempurna. Secara ekonomi, hasil simulasi peningkatan kapasitas menjadi 3000 ayam per hari pada penyembelihan skala menengah menggunakan shackle conveyor dapat mengurangi Harga Pokok Produksi (HPP) menjadi Rp 22.029 dan harga jual menjadi Rp 28.638 per ayam. Di sisi lain, simulasi peningkatan kapasitas menjadi 300 ayam per hari pada penyembelihan skala kecil perlu menambah alat pengantung ayam sederhana untuk mengatasi HCP pengumpulan ayam pasca penyembelihan. Hal ini menyebabkan HPP menjadi Rp 22.016 dan harga jual Rp 28.621 per ayam. Pilihan alat penyembelihan ayam sesuai kapasitas produksi mendukung implementasi SJH secara efisien untuk memperoleh produk kompetitif.
\end{abstract}

Kata kunci: alat penyembelih, ayam, kapasitas, HCP, sistem jaminan halal

\section{PENDAHULUAN}

Pasar produk halal dunia terus meningkat, diantaranya produk pangan. Penduduk Indonesia sebagian besar beragama Islam menjadi bermasalah jika mengkonsumsi pangan dari ternak yang disembelih tanpa mengikuti cara Islam (Gumilar dan Pratama, 2018). Peluang ini belum optimal dimanfaatkan pelaku usaha, khusunya Usaha Mikro Kecil dan Menengah (UMKM). Di Indonesia dari sekitar 54 juta UMKM, baru sekitar 3000 tersertifikasi halal. Hal ini karena konsumen dan 
produsen belum cukup loyal terhadap produk halal, meski loyalitasnya cenderung naik. Berdasar UU No 33 Tahun 2014 tentang Jaminan Produk Halal (JPH) produk pangan yang beredar di Indonesia mesti bersertifikat halal. Pemberlakuan UU tersebut dapat berdampak bagi pengusaha yang produknya belum tersertifikasi halal (Fauziyah et al., 2017).

Menurut data Direktorat Jenderal Peternakan dan Kesehatan Hewan (PKH) Kementerian Pertanian, konsumsi daging ayam ras per kapita per tahun pada 2015-2016 meningkat dari 4,797 menjadi $5,110 \mathrm{~kg}$. Konsumsi daging ayam ras ini paling besar dibanding konsumsi jenis daging lain (Anonimous, 2017). Seiring peningkatan jumlah penduduk, kebutuhan pangan halal meningkat. Peluang penyembelihan ayam bersertifikasi halal semakin besar.

Kehalalan daging ayam ditentukan oleh implementasi Sistem Jaminan Halal (SJH) selama produksi. Produksi daging ayam halalan thoyibban perlu dijamin dengan beberapa regulasi dan aturan teknis. Standar rumah potong unggas (Badan Standar Nasional, 1999). Mutu karkas daging ayam (Badan Standar Nasional, 2009). Pedoman SJH untuk Rumah Potong Hewan (LPPOM MUI, 2012). Persyaratan pemotongan unggas dan penanganan hasilnya (Surat Keputusan Menteri Pertanian No 306/KPTS/TN.330/4/1994). Kompetensi kerja penyembelihan hewan halal (Keputusan Menteri Tenaga Kerja dan Transmigrasi RI No 196 Tahun 2014). Berbagai aturan ini telah mengatur secara memadai proses penyembelihan meliputi pemeriksaan ante mortem, penyembelihan, dan pemeriksaan post mortem. Alat penyembelihan dan ketrampilan penyembelih juga sudah ditentukan.

Penerapan peraturan-peraturan tersebut di lapang mengalami kendala karena usaha penyembelihan banyak berskala kecil dan belum terstandar. Hal ini menimbulkan ketidakpastian jaminan halal daging ayam di masyarakat. Pengamatan awal Majelis Ulama Indonesia (MUI) Bangkalan Jawa Timur menyebutkan ada 8 ayam dari 10 ayam yang dibeli dari pasar, penyembelihannya dianggap tidak sah (Anonimous, 2018). Penyembelihan ayam yang dijamin halal dengan harga bersaing penting diterapkan dan terus dikembangkan. Hal ini dilakukan dengan identifikasi Halal Control Point (HCP) pada produksi daging ayam, kapasitas produksi, alat penunjang penyembelihan, proses penyembelihan, dan penanganan pasca penyembelihan. Pemilihan alat penyembelihan dengan kapasitas tepat akan menghasilkan efisiensi produksi sehingga menghasilkan ayam dengan harga bersaing. Penelitian ini bertujuan untuk memilih alat penunjang penyembelihan ayam yang tepat sesuai kapasitas produksi berdasar aspek teknoekonomi untuk mendukung penerapan SJH.

\section{METODE PENELITIAN}

Penelitian ini dilakukan di tempat penyembelihan ayam skala menengah Mualim Broiler Batu dan skala kecil yaitu Amanah dan H.Busri di Surabaya. Pengolahan data di Laboratorium Komputasi dan Analisis Sistem, Jurusan Teknologi Industri Pertanian, Fakultas Teknologi Pertanian, Universitas Brawijaya.

Penelitian menggunakan metode diskriptif analitik untuk mendapat data kualitatif dan kuantitatif. Data diperoleh dengan tahap observasi dan dokumentasi di lapang, wawancara dengan pelaku usaha dan pihak terkait. Observasi untuk mendapat informasi kapasitas produksi, penerimaan ayam hingga pasca penyembelihan, alat penyembelihan ayam, mesin, dan alat pendukung lain. Hal ini terkait jumlah, biaya investasi, kapasitas per batch per mesin, dan umur ekonomis mesin. Wawancara untuk identifikasi penerapan aspek teknis sesuai syarat halal Lembaga Pengkajian Pangan, Obat-obatan, dan Kosmetika - Majelis Ulama Indonesia (LPPOM MUI) dan kelayakan ekonomi di tempat penyembelihan. Data hasil wawancara dengan pengusaha berupa kebutuhan listrik, air, dan utilitas setiap hari. Jumlah dan gaji karyawan, harga bahan baku dan harga jual produk, dan investasi. Berbagai komponen di atas digunakan untuk menentukan biaya tetap, biaya variabel, dan biaya overhead. Berikutnya adalah menentukan Harga Pokok Produksi (HPP) dan harga jual. Penyusutan setiap tahun dihitung berdasar investasi dan umur alat. Biaya perawatan berdasarkan persentase dari biaya investasi. Dokumentasi untuk mengumpulkan foto dan literatur pendukung. Penelitian dibatasi pada anasilis biaya parsial alternatif pilihan alat penyembelihan ayam berdasar simulasi kapasitas produksi.

\section{HASIL DAN PEMBAHASAN}

\section{Kondisi Penyembelihan Ayam}

Usaha penyembelihan ayam Amanah (A) didirikan tahun 1960 dan dikelola H. Muntamin dan orang tuanya. Usaha ini berlokasi di lantai dasar pasar DTC Wonokromo, Jagir, Surabaya. Luas tempat penyembelihan ayam sekitar $15 \times 1,5 \mathrm{~m}^{2}$ dan tempat menjual karkas ayam sekitar $4 \times 2 \mathrm{~m}^{2}$. Daging dan karkas ayam dipasarkan ke usaha katering dan dijual di tempat sendiri. Usaha ini beroperasi jam 03.3014.00 WIB. Usaha telah memiliki legalitas berupa Surat Izin Usaha Perdagangan (SIUP), surat izin hak guna dari manajemen Perusahaan Daerah Pasar Surya Surabaya, surat izin usaha potong hewan dari Dinas Perikanan, Kelautan, Peternakan, Pertanian, dan Kehutanan Kota Surabaya dan sertifikat halal.

Usaha penyembelihan ayam H. Busri (B) di pasar Baba'an Jalan Kebalen Timur, Krembangan, Kota Surabaya. Usaha ini dimulai tahun 1975 di pasar Pabean, Pabean Cantian, Kota Surabaya. Usaha ini dikelola H. Busri hingga tahun 1980 pindah ke pasar 
Baba'an. Sekitar tahun 2010 usaha ini dikelola oleh H. Busri dan anaknya yakni Bapak Zamroni sampai saat ini. Luas tempat penyembelihan sekitar $5 \times 2 \mathrm{~m}^{2}$. Daging ayam, bebek, dan karkas dipasarkan di Kota Surabaya dan sempat mengirim ke Makasar tahun 2012. Jam operasi 04.00-11.00 WIB. Bentuk legalitas berupa SIUP dan pernah memiliki sertifikat halal sampai 2014.

Penyembelihan Mualim Broiler (C) di Pandanrejo Kota Batu dikelola Bapak Didit sekaligus sebagai manajer. Saat ini, Mualim Broiler memiliki lahan $600 \mathrm{~m}^{2}$ dibagi menjadi kantor, produksi, dan parkir. Produk daging dan karkas ayam dipasarkan ke beberapa kota besar wilayah Indonesia Timur seperti Balikpapan dan Samarinda. Konsumen tetap diantaranya Kentucky Fried Chicken (KFC), Hero Supermarket, dan beberapa restoran di Malang Raya. Jam operasi Mualim Broiler jam 08.00-17.00 WIB dan waktu istirahat jam 12.00-13.00 WIB. Legalitas yang dimiliki berupa SIUP, nomor pokok wajib pajak (NPWP), nomor kesehatan veteriner (NKV), izin gangguan atau hinderordonnantie (HO), tanda daftar perusahaan (TDP), dan sertifikat halal.

Menurut Singgih dan Kariana (2008) rumah potong ayam menjalankan fungsi penyembelihan ayam hidup dan mengolah menjadi karkas siap konsumsi. Menurut Jeon et al. (2013) rumah potong ayam merupakan bangunan tempat penyembelihan ayam mencakup penghilangan bulu, kotoran dan limbah lain.

Deskripsi produk mencakup nama jenis produk, konsumen yang dituju, dan cara penggunaan (Apriyantono et al., 2007). Produk ketiga penyembelihan ayam berupa karkas, daging ayam, jerohan, kepala, sayap dan ceker. Surat Keputusan Menteri Pertanian No 306/KPTS/TN.330/4/1994 menjelaskan produk penyembelihan unggas meliputi karkas, jerohan, dan hasil ikutan. Produk penyembelihan skala kecil dipasarkan di Surabaya, sedang penyembelihan skala menengah Mualim Broiler dipasarkan ke Malang Raya, Jawa Timur, dan wilayah Indonesia Timur. Cara mengkonsumsi produk ini dimasak lebih dahulu karena merupakan produk mentah. Semua produk merupakan produk Aman, Sehat, Utuh, Halal (ASUH).

\section{Teknis Produksi dan Identifikasi Halal Control Point (HCP)}

Regulasi teknis produksi daging ayam di Indonesia diatur dalam Surat Keputusan Menteri Pertanian N0 306/KPTS/TN.330/4/1994 tentang pemotongan unggas dan penanganan daging unggas serta hasil ikutannya. Secara umum, penyembelihan unggas meliputi pemeriksaan ante mortem, penyembelihan, penyelesaian penyembelihan, dan pemeriksaan post mortem. Pemeriksaan ante mortem secara sederhana dengan seksama mengamati kondisi fisik, suara, dan bulu unggas, serta gejala klinis yang tampak. Meski sudah diatur dengan peraturan yang jelas, fakta di lapang dijumpai kondisi penyembelihan ayam tidak terstandar.

Proses produksi daging ayam di usaha skala kecil (A dan B) meliputi penerimaan dan seleksi ayam hidup, pengistirahatan, penyembelihan, pengumpulan ayam pasca penyembelihan di tong, pencelupan air panas, pencabutan bulu, pengeluaran jeroan, pembersihan, dan pemotongan karkas. Secara skematis proses produksi ayam di skala kecil seperti pada Gambar 1.

HCP penyembelihan ayam skala kecil tanpa stunning terdapat pada tahap penyembelihan dan pengumpulan di tong. HCP penyembelihan ayam telah diteliti (Shahdan et al., 2016 dan Shahdan et al., 2017), diantaranya disebabkan tahap pasca penyembelihan hingga kematian sempurna. Pada tahap penyembelihan dijumpai 5 persen hasil penyembelihan tidak sempurna, karena salah satu dari saluran nafas, saluran makanan, dan dua urat nadi belum terputus. Bahkan, hasil penelitian awal oleh MUI Bangkalan menyebutkan 8 dari 10 sampel ayam yang dibeli di pasar tidak terpotong salah satu salurannya (Anonimous, 2018). Nakyinsige et al. (2013) dan Keputusan Menteri Pertanian RI No 306/KPTS/TH.330/4/1994 menyebutkan penyembelihan Islami seharusnya memotong dengan sempurna pembuluh darah vena jugularis dan arteri karotis, trakea (saluran nafas), dan esophagus (saluran makanan). Selain itu, pengumpulan ayam bertumpuktumpuk pasca penyembelihan dalam tong kurang menjamin aspek kesejahteraan hewan dan kesempurnaan pengeluaran darah. Aspek kesejahteraan hewan sangat diperhatikan saat menyembelih tanpa stunning. Diantaranya adalah nyeri dan stres pasca penyembelihan (Gregory et al., 2008). Aspek kesejahteraan hewan juga diatur dalam regulasi halal di Indonesia seperti pada standar rumah potong unggas (Badan Standar Nasional, 1999). Kondisi di atas sangat krusial karena terkait aspek kesejahteraan hewan, kehalalan, dan keamanan daging ayam hasil sembelihan. Pengendalian diantaranya dengan menambah alat gantung ayam untuk menjamin ayam tersembelih sempurna. Alat gantung ini berfungsi menyempurnakan pengeluaran darah pasca penyembelihan.

Proses produksi daging ayam skala menengah meliputi penerimaan, seleksi ayam, penggantungan, stunning, penyembelihan, perebusan, pengguntingan kaki, pencabutan bulu, pemotongan kepala, pengambilan jeroan, pencucian awal, sortasi, pre-chilling, parting, pengemasan, dan pembekuan. Secara teoritis HCP penyembelihan ayam skala menengah pada tahap penggantungan, stunning, dan penyembelihan. Stunning di tempat penelitian dilakukan dengan listrik. Stunning dengan listrik adalah salah satu metode stunning yang paling banyak digunakan (Gregory, 2007; Zivotofsky dan Strous, 2012). 


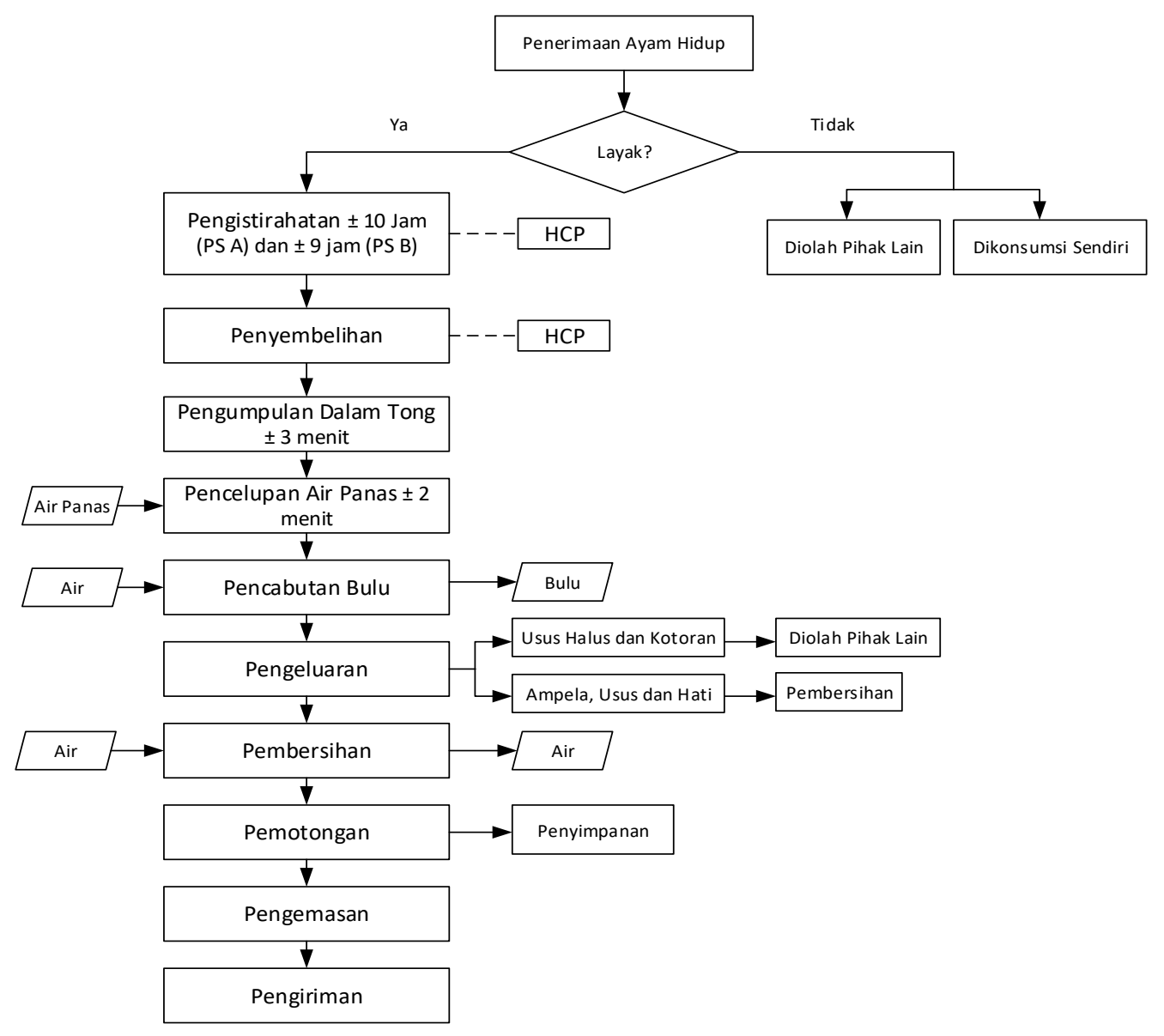

Gambar 1. Proses produksi daging ayam di skala kecil

Dalam penyembelihan secara Islami stunning dibolehkan jika memenuhi beberapa syarat. Fatwa MUI No 12 Tahun 2009 tentang penyembelihan halal (MUI, 2009) membolehkan stunning untuk membuat hewan pingsan sementara (tidak permanen), dalam rangka berbuat baik pada hewan, dan alat pemingsan hanya digunakan untuk hewan halal. Hal senada disyaratkan pada prosedur pemingsanan di Malaysia. Pertama alat pemingsanan dikontrol pengawas Muslim terlatih (MS1500, 2009). Kedua, stunning tidak membuat kematian (MS1500, 2009). Ketiga, stunning hewan haram tidak untuk hewan halal (MS1500, 2004). Pada tempat penelitian, HCP dapat dikontrol selama produksi, sehingga tempat penyembelihan skala menengah sudah tersertifikasi halal.

\section{Kapasitas, Mesin dan Peralatan Produksi}

Kapasitas produksi penyembelihan ayam skala kecil Amanah rata-rata 70-150 ekor per hari, sedang di H Busri 100-150 ekor per hari. Ketika kondisi pasar bagus (bulan Ramadhan, menjelang natal, dan tahun baru) kadang menyembelih hingga 300 ekor per hari. Produksi di penyembelihan skala menengah Mualim Broiler mencapai 2000 ekor per hari atau setara 3 ton daging ayam per hari. Kapasitas tersebut didukung mesin dan peralatan cukup baik, sehingga mencapai kapasitas maksimal. Kapasitas ini relatif tetap karena telah memiliki konsumen tetap.

Jenis mesin dan alat disesuaikan kapasitas produksi. Menurut Tieman et al. (2013) semakin kompleks teknologi pengolahan, semakin banyak faktor yang memengaruhi kehalalan produk, diantaranya bahan, proses pengolahan, sarana, dan pengangkutan. Menurut Shahdan et al. (2016) salah satu HCP penyembelihan adalah alat potong yang digunakan. Mesin dan peralatan penyembelihan ayam skala kecil di tempat penelitian dapat dilihat pada Tabel 1. Keterbatasan alat penyembelihan ayam skala kecil menyebabkan kehalalan dan keamanan daging ayam hasil sembelihan masih belum terjamin

Penyembelihan ayam skala menengah perlu mesin dan alat lebih banyak dan lebih kompleks, baik manual maupun semi otomatis seperti pada Tabel 2. Beberapa alat dan mesin didesain pengusaha sesuai kebutuhan. Mesin tersebut yakni scalder, hanger bleeding, dan plucker. Mesin dan peralatan terbuat dari stainless steel agar saat kontak dengan bahan tidak mudah korosif. Stainless steel memiliki ketahanan korosi yang baik karena memiliki lapisan permukaan krom. Bahan ini juga sering digunakan di industri makanan dan alat makan.

Alat untuk proses stunning dan ketajaman pisau sangat menentukan status kehalalan hasil 
sembelihan. Shahdan et al. (2016) mengatakan salah satu penentu HCP penyembelihan adalah alat potong yang digunakan.

Tabel 1. Mesin dan Peralatan Skala Kecil

\begin{tabular}{|c|c|c|c|c|}
\hline \multirow[t]{2}{*}{ Nama Mesin } & \multicolumn{2}{|c|}{ Amanah } & \multicolumn{2}{|c|}{ H.Busri } \\
\hline & Jumlah & Jenis & Jumlah & Jenis \\
\hline Plucker & 1 & Ss & 1 & Ss \\
\hline Diesel & & & & \\
\hline Tungku & 2 & $\mathrm{Be}$ & 2 & $\mathrm{Be}$ \\
\hline Cooling Storage & 1 & - & 2 & - \\
\hline Keranjang & 2 & $\mathrm{Bb}$ & 2 & $\mathrm{Bb}$ \\
\hline Dandang & 2 & Ss & 2 & $\mathrm{Db}$ \\
\hline Pisau & 3 & $\mathrm{Ba}$ & 3 & $\mathrm{Ba}$ \\
\hline
\end{tabular}

Keterangan:

Ba: Baja $\quad$ Bb: Bambu Db: Drum bekas

Be: Besi $\quad$ Ss: Stainless steel

Tabel 2. Mesin dan peralatan skala menengah

\begin{tabular}{lll}
\hline Nama Mesin & Jumlah & Jenis Bahan \\
\hline $\begin{array}{l}\text { Hanger Bleeding } \\
\text { dan Stunner }\end{array}$ & 1 & Stainless steel \\
$\begin{array}{l}\text { Scalder } \\
\text { Meja Kerja (1) }\end{array}$ & 1 & Stainless steel \\
Plucker & 1 & Stainless steel \\
Meja Kerja (2) & 1 & Stainless steel \\
Metal Detector & 3 & Stainless steel \\
Parting Machine & 2 & - \\
Water Washing & 1 & Stainless steel \\
Blast Freezer & 1 & Stainless steel \\
Cold Storage & 1 & Stainless steel \\
Pisau sembelih & 1 & - \\
Pisau bedah perut & 3 & Baja \\
Gunting Karakas & 1 & Nikel \\
Garpu eviserasi & 3 & Baja \\
Keranjang & 10 & Stainless steel \\
\hline
\end{tabular}

\section{Tenaga Kerja dan Utilitas}

Jumlah tenaga kerja di setiap penyembelihan ayam berbeda sesuai kapasitas produksi dan mesin yang dioperasikan. Penyembelihan ayam skala kecil rata-rata membutuhkan 4-6 orang, sedang penyembelihan ayam skala menengah membutuhkan
20 orang. Setiap tenaga kerja mendapat gaji sekitar Rp 1.500.000 per bulan.

Utilitas di penyembelihan ayam skala kecil berupa air, listrik, dan Liquid Petroleum Gas (LPG). Tarif air dan listrik sesuai standar di Surabaya dan dibayar ke pengelola pasar. Utilitas penyembelihan skala menengah berupa air dari Perusahaan Daerah Air Minum (PDAM) dan listrik dari genset milik usaha penyembelihan. Hal ini terkait analisis teknoekomomi yang dilakukan.

\section{Biaya Investasi}

Menurut Halkin et al. (2017) biaya investasi yang rasional membantu memperbaiki manajemen dan perencanaan usaha jangka panjang. Total biaya investasi penyembelihan ayam skala kecil Amanah dan H. Busri berbeda, yakni masing-masing sebesar Rp 11.260.000 dan Rp 11.060.000. Perbedaan tersebut karena bahan kuali berbeda. Biaya investasi selengkapnya pada Tabel 3. Investasi merupakan penanaman modal usaha untuk membeli barangbarang modal dan perlengkapan produksi agar menambah kemampuan produksi (Sukirno, 2005). Menurut Mahendra (2010) semakin besar kapasitas produksi semakin besar investasi perusahaan. Total biaya investasi di penyembelihan Mualim Broiler Rp 922.000.000.

\section{Biaya Produksi}

Biaya produksi atau operasi untuk memenuhi keperluan harian, bulanan, atau tahunan (Brealey et al., 2007). Biaya produksi penyembelihan ayam skala kecil Amanah sebesar Rp 1.230.227.380 per tahun dan H.Busri Rp 1.265.978.467 per tahun. Perbedaan tersebut karena bahan mesin dan jumlah tenaga kerja berbeda. Selisih keduanya yakni Rp 35.751.167. Penyembelihan Mualim Broiler mengeluarkan biaya produksi setahun Rp 16.198.388.254. Biaya produksi per tahun dipengaruhi kapasitas produksi (Tabel 4).

$\underline{\text { Tabel 3. Biaya investasi pada beberapa skala produksi }}$

\begin{tabular}{lrrr}
\hline \multicolumn{1}{c}{ Uraian } & \multicolumn{2}{c}{$\begin{array}{c}\text { Penyembelihan } \\
\text { Skala Kecil }\end{array}$} & $\begin{array}{c}\text { Penyembelihan } \\
\text { Skala Menengah }\end{array}$ \\
\cline { 2 - 4 } & Amanah (Rp) & H. Busri (Rp) & Mualim Broiler (Rp) \\
\hline Plucker & 3.500 .000 & 3.000 .000 & 10.000 .000 \\
Tungku & 200.000 & 200.000 & \\
Cooling Storage & 4.000 .000 & 1.400 .000 & 300.000 .000 \\
Kuali/ Dandang & 3.000 .000 & 300.000 & \\
Pisau & 60.000 & 60.000 & 140.000 \\
Hanger Bleeding dan stunner & & & 30.000 .000 \\
Scalder & & & 15.000 .000 \\
Metal Detector & & & 1.700 .000 \\
Parting Machine & & & 13.000 .000 \\
Water Washing & & & 12.000 .000 \\
Blast Freezer & & & 300.000 .000 \\
Meja Kerja & & & 4.500 .000 \\
Gunting Karkas & & & 40.000 \\
Garpu eviserasi & & & 150.000 \\
\hline Total & & & 922.000 .000 \\
\hline
\end{tabular}


Komponen biaya produksi terdiri dari fixed cost, variable cost, dan overhead cost (Ardianti, 2015). Komponen biaya tersebut dibagi menjadi biaya tetap meliputi biaya reinvestasi, penyusutan, dan pemeliharaan. Biaya variabel berupa biaya utilitas, bahan baku, gaji tenaga kerja, dan biaya overhead meliputi biaya audit internal dan pemeliharaan sertifikasi halal.

\section{Harga Pokok Produksi (HPP) dan Harga Jual}

Perhitungan Harga Pokok Produksi (HPP) yang tepat perlu dilakukan setiap usaha. Tanpa perhitungan HPP yang tepat, usaha mengalami masalah penentuan harga jual produk (Setiadi et al., 2014). Hasil perhitungan HPP per ekor ayam di penyembelihan ayam Amanah Rp 22.782 dan H.Busri Rp 23.444.

Menurut Kotler dan Keller (2009) harga jual dibebankan atas suatu produk atau jasa, atau nilai yang ditukar konsumen atas manfaat, karena menggunakan produk atau jasa. Mark up atau keuntungan dianggap wajar sebesar 30\% (Kondoy et al., 2015). Berdasarkan hal ini harga jual ditetapkan Rp 29.617 per ekor untuk penyembelihan ayam Amanah, Rp 30.477 untuk H.Busri, dan Mualim Broiler sebesar Rp 29.247.

\section{Simulasi Kapasitas dan Pilihan Alat Penyembelihan}

Saat penelitian, penyembelihan ayam skala kecil berkapasitas 150 ekor per hari perlu 4 tenaga kerja dan utilitas berupa air, listrik dan LPG. Mesin dan alat menggunakan plucker dan diesel, tungku, cooling storage, keranjang, kuali, dan pisau. Total biaya investasi Rp 11.260.000. Hasil perhitungan finansial HPP Rp 22.782 dan dengan mark up 30\% menghasilkan harga jual Rp 29.617 per ekor ayam.

Penyembelihan ayam skala menengah berkapasitas 2000 ekor per hari perlu mesin dan alat hanger bleeding dan stunner, scalder, plucker, metal detector, parting machine, water washing, blast freezer, cold storage, meja kerja, pisau sembelih, pisau bedah perut, gunting karkas, garpu eviserasi, dan keranjang. Usaha ini perlu 20 tenaga kerja dan utilitas berupa air dan listrik. Total biaya investasi Rp 16.198.388.254. HPP Rp 22.498 dan dengan mark up $30 \%$ diperoleh harga jual Rp 29.247 per ekor ayam.

Hasil penelitian di atas menunjukkan penyembelihan ayam skala kecil belum memenuhi syarat untuk mendukung penerapan $\mathrm{SJH}$, terutama pada bagian penegluaran darah pasca penyembelihan. Syarat tersebut dapat terpenuhi dengan menambah alat penggantung (shcakle) sederhana dengan meningkatkan kapasitas produksi. Penyembelihan skala menengah ditingkatkan efisiensinya dengan alat shackle conveyor T-track sehingga mempercepat proses produksi dan mengurangi tenaga kerja. Oleh karena itu dilakukan simulasi peningakatan kapaistas dan memilih alat yang ekonomis.

Simulasi peningkatan kapasitas dan alternatif pilihan alat penyembelihan ayam skala kecil untuk mengatasi HCP pengeluaran darah pasca penyembelihan sehingga sesuai SJH. Kapasitas penyembelihan ayam Amanah 150 ekor per hari, sedang kapasitas maksimum 300 ekor per hari. Karena itu, simulasi penyembelihan ayam skala kecil ditentukan 300 ekor per hari. Saat ini, setelah ayam disembelih diletakkan dalam tong sehingga rawan penumpukan yang dapat mengakibatkan ayam mati bukan karena darah keluar sempurna.

Tabel 4. Biaya produksi per tahun pada beberapa skala produksi

\begin{tabular}{|c|c|c|c|c|}
\hline \multirow[t]{2}{*}{ Komponen Biaya Produksi } & \multicolumn{3}{|c|}{$\begin{array}{c}\text { Penyembelihan } \\
\text { Skala Kecil }\end{array}$} & \multirow{2}{*}{$\begin{array}{c}\text { Penyembelihan } \\
\text { Skala Menengah } \\
\text { Mualim Broiler }\end{array}$} \\
\hline & Amanah (A) & H. Busri (B) & $\Delta(\mathbf{A}-\mathrm{B})$ & \\
\hline \multicolumn{5}{|l|}{ Biaya Tetap } \\
\hline a. Biaya Reinvestasi & 3.010 .000 & 2.860 .000 & 150.000 & 92.012 .857 \\
\hline b. Biaya Penyusutan & 1.762 .500 & 1.666 .667 & 95.833 & 82.826 .497 \\
\hline c. Biaya Pemeliharaan & 334.800 & 331.800 & 3.000 & 27.660 .900 \\
\hline Total Biaya Tetap & 5.107 .300 & 4.858 .467 & 35.751 .167 & 202.500 .254 \\
\hline \multicolumn{5}{|l|}{ Biaya Variabel } \\
\hline a. Utilitas & 15.120 .000 & 15.120 .000 & & 510.888 .000 \\
\hline b. Bahan Baku & 1.134 .000 .000 & 1.134 .000 .000 & & 15.120 .000 .000 \\
\hline c. Tenaga Kerja Langsung & 72.000 .000 & 108.000 .000 & 36.000 .000 & 360.000 .000 \\
\hline Total Biaya Variabel & 1.221 .120 .000 & 1.257.120.000 & 36.000 .000 & 15.990 .888 .000 \\
\hline \multicolumn{5}{|l|}{ Biaya Overhead } \\
\hline $\begin{array}{l}\text { Biaya audit internal dan } \\
\text { pemeliharaan sertifikasi halal }\end{array}$ & 4.000 .000 & 4.000 .000 & - & 5.000 .000 \\
\hline Total Biaya Overhead & 4.000 .000 & 4.000 .000 & - & 5.000 .000 \\
\hline Total Biaya Produksi & 1.230 .227 .300 & 1.265 .978 .467 & 35.751 .167 & 16.198 .388 .254 \\
\hline
\end{tabular}


Menurut Kirton et al. (1981) darah keluar sempurna merupakan salah satu indikator hewan mati. Untuk mengurangi resiko tersebut perlu mesin dan alat meliputi plucker dan diesel, tungku, cooling storage, shackle sederhana, keranjang, kuali atau dandang, dan pisau untuk kapasitas 300 ekor per hari. Simulasi usaha ini perlu 4 tenaga kerja dan utilitas berupa air, listrik, dan LPG. Total biaya investasi meningkat menjadi Rp 12.760.000, HPP sebesar Rp 22.016, dan harga jual Rp 28.621 per ekor ayam.

Simulasi penyembelihan skala menengah dengan kapasitas mencapai 3000 ekor per hari menggunakan pilihan alat shackle conveyor T-track dapat mengurangi tenaga kerja 2 orang menjadi 18 orang per hari. Secara lengkap, mesin dan alat yang digunakan yakni shackle conveyor T-track dan Stunner, scalder, plucker, metal detector, parting machine, water washing, blast freezer, cold storage, meja kerja, pisau sembelih, pisau bedah perut, gunting karkas, garpu eviserasi dan keranjang. Total biaya investasi Rp 1.234.196.800, HPP sebesar Rp 22.029, dan harga jual menjadi Rp 28.638. Tabel 5 menunjukkan biaya untuk setiap pilihan investasi alat penyembelih dan kapasitas produksi kondisi saat penelitian dan hasil simulasi.

Penyembelihan skala kecil memiliki perbedaan investasi alat dan biaya produksi. Saat penelitian, penyembelihan Amanah tidak menggunakan alat gantungan (shackle) sederhana seperti kondisi simulasi. Hal tersebut berakibat pada perbedaan biaya investasi hasil simulasi, khususnya biaya tetap (reinvestasi, penyusutan dan pemeliharaan). Perbedaan kapasitas berimbas pada biaya variabel bahan baku. Utilitas di penyembelihan skala kecil cenderung tetap untuk air dan listrik, namun kebutuhan LPG berubah dari 2 menjadi 4 buah sehingga biayanya menjadi Rp 28.080.000 per tahun (Tabel 6).

Tabel 5. Pilihan investasi dan kapasitas produksi saat penelitian dan simulasi

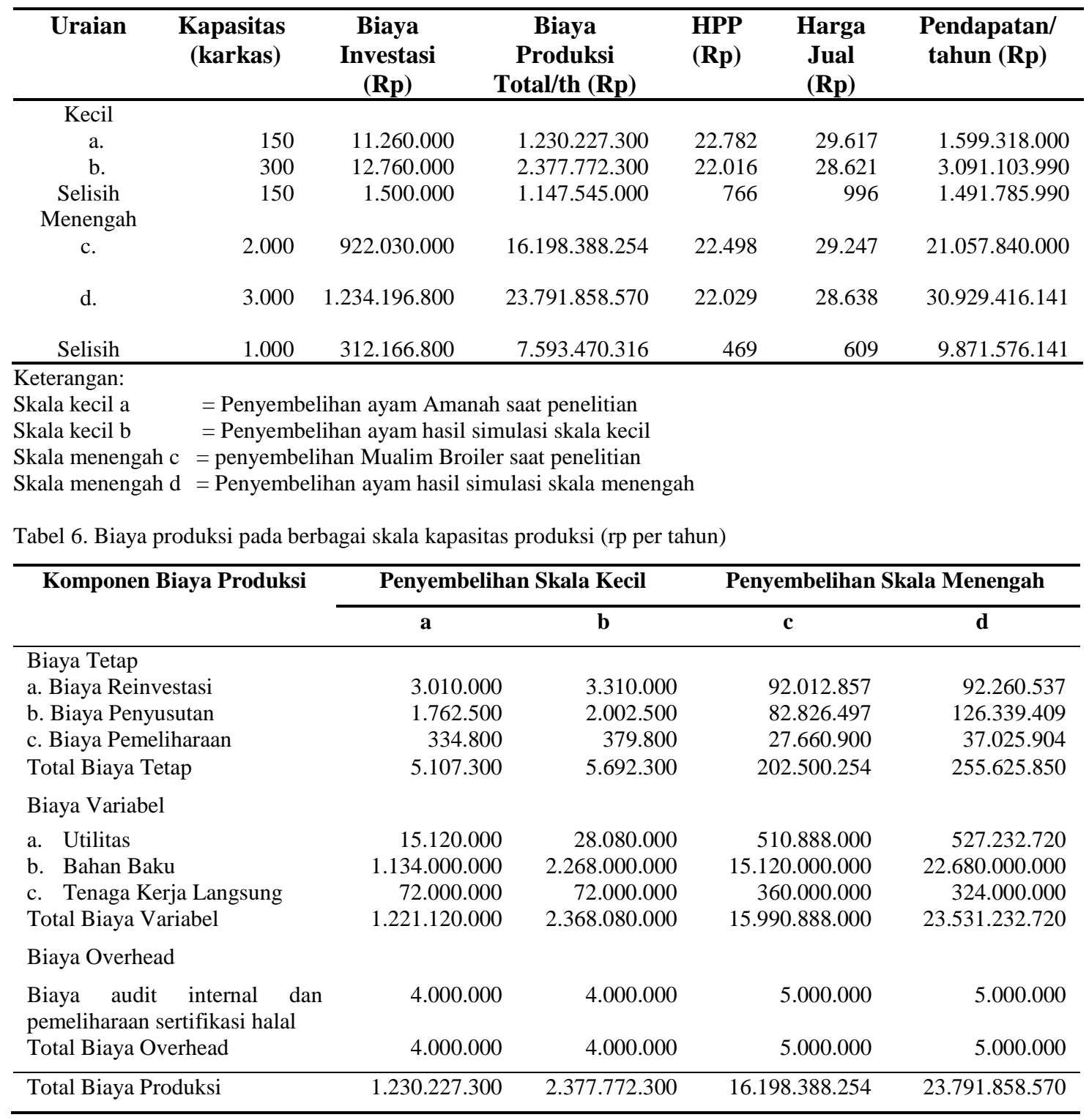


Simulasi peningkatan kapasitas dan investasi alat baru di penyembelihan skala menengah (d) membuat biaya tetap (reinvestasi, penyusutan dan pemeliharaan) meningkat menjadi Rp 255.625.850. Investasi alat baru dapat mengurangi 2 orang tenaga kerja di bagian produksi, sehingga biaya tenaga kerja langsung menjadi Rp 324.000.000. Penambahan conveyor di penyembelihan skala menengah meningkatkan biaya utilitas menjadi Rp 527.232.720 per tahun. Asumsi conveyor T-Track bekerja 6,25 jam per hari dengan daya 2,25 kwh per hari. Mengacu tarif daftar listrik Rp 1.112 per kwh maka kebutuhan listrik untuk conveyor per bulan Rp 75.060 dan biaya air untuk mencuci ayam juga meningkat.

Salah satu pertimbangan penyembelihan hewan agar memenuhi syarat halal adalah darah keluar sempurna pasca penyembelihan (Fuseini et al, 2016). Penggantungan ayam lebih menyempurnakan pengeluaran darah. Menurut Fatwa MUI No 12 tahun 2009, penyembelihan yang baik karena terputus saluran darah, kerongkongan, dan tenggorokan (MUI, 2009; Delfita, 2013). Kondisi tersebut menyebabkan darah dapat keluar sempurna. Penyembelihan skala menengah dengan menggantung ayam pasca penyembelihan merupakan praktek produksi yang sudah berjalan dengan baik untuk diadopsi oleh penyembelihan skala kecil dengan modifikasi alat gantung (shackle) ayam sederhana seperti Gambar 2.

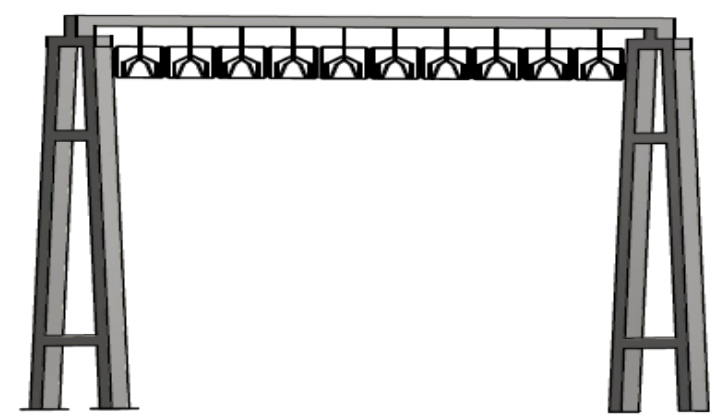

Gambar 2. Alat Gantungan (shackle) sederhana

Alat shackle sederhana terbuat dari stainless steel dengan 10 buah shackle. Setiap shackle untuk 2 ayam sehingga dapat mengantung ayam 20 ekor. Alat ini dipilih berdasar waktu mati ayam pasca penyembelihan dan kapasitas produksi hasil simulasi. Kelebihan alat ini memiliki investasi relatif kecil dan mencukupi untuk penyembelihan ayam skala kecil. Kekurangan alat ini masih memungkinkan ayam yang belum disembelih melihat ayam lain saat disembelih karena penyembelihan ayam tanpa stunning. Menurut Rony dan Etwin (2017) idealnya ayam mati 3-5 menit pasca penyembelihan tanpa stunning. Hitungan ini dipilih karena penyembelihan ayam skala kecil tanpa stunning. Investasi shackle sederhana sekitar Rp 1.500.000, dapat dipilih ketika kapasitas produksi 300 ekor per hari agar harga jual ayam dapat bersaing.
Shahdan et al. (2016) menyatakan HCP penyembelihan ayam salah satunya adalah penirisan darah pasca penyembelihan. Bila darah keluar sempurna maka daging tidak mengandung darah atau mikroorganisme di darah sehingga mutu daging lebih bagus. Pengeluaran darah sempurna selain memenuhi aspek SJH juga menghasilkan mutu karkas ayam yang baik.

Implementasi hasil simulasi penambahan alat penyembelihan ini masih membutuhkan analisis lebih lanjut karena akan mempengaruhi ketersediaan ruang produksi, serapan pasar, ketersediaan modal kerja, dan penanganan limbah. Dari aspek pasar masih sangat terbuka karena permintaan daging ayam terus meningkat seiring peningkatan jumlah penduduk Indonesia. Di sisi lain, daging ayam banyak disukai konsumen karena harganya relatif murah dan kandungan gizi cukup baik. Dari ketersedian ruang produksi alat penggantung (shackle) sederhana tidak memakan tempat sehingga masih dapat ditempatkan pada ruang yang ada saat ini. Untuk penanganan limbah dan modal kerja membutuhkan analisis lebih lanjut karena belum dilakukan pada penelitian ini.

\section{KESIMPULAN DAN SARAN}

\section{Kesimpulan}

Penyembelihan ayam skala menengah memiliki Halal Control Point (HCP) terutama saat stunning, sedang skala kecil memiliki HCP penirisan darah pasca penyembelihan. Aspek teknoekonomi pilihan alat penyembelihan ayam telah dilakukan simulasi kapasitas. Simulasi dengan peningkatan kapasitas dari 2.000 menjadi 3.000 ekor per hari pada penyembelihan skala menengah perlu mengganti alat hanger bleeding menjadi shackle conveyor sehingga dapat mengurangi 2 tenaga kerja bagian produksi. Total investasi Rp 1.234.196.800, modal kerja setahun Rp 23.791.858.570, HPP Rp 22.029 dan harga jual Rp 28.638 per ekor ayam. Simulasi peningkatan kapasitas dari 150 menjadi 300 ekor per hari pada penyembelihan ayam skala kecil perlu inventasi alat gantung sederhana untuk mengatasi HCP pengumpulan ayam di tong pasca penyembelihan hingga dapat mengeluarkan darah dan mati sempurna. Hal ini berkonsekuensi pada biaya investasi Rp 12.760.000, modal kerja setahun Rp 2.377.772.300, HPP Rp 22.016 dan harga jual Rp 28.621 per ekor ayam. Pilihan alat pada setiap skala produksi mendukung penyembelihan sesuai Sistem Jaminan Halal (SJH).

\section{Saran}

Harga pengantung ayam sederhana tergantung kapasitas dan jenis bahan. Karena itu perlu diteliti berbagai alternatif pengantung ayam yang memengaruhi biaya investasi. Tulisan ini belum membahas aspek sanitasi penyembelihan ayam skala 
kecil, dampak peningkatan kapasitas terhadap modal kerja dan penanganan limbah sehingga perlu diteliti lebih lanjut. Pengusaha penyembelihan ayam perlu mempertimbangkan aspek-aspek di atas sebelum menerapkan hasil riset ini.

\section{UCAPAN TERIMA KASIH}

Penulis mengucapkan terima kasih kepada Kementerian Riset, Teknologi, dan Pendidikan Tinggi, serta Universitas Brawijaya yang telah memberikan dukungan penelitian dan publikasi.

\section{DAFTAR PUSTAKA}

Anonimous. 2017. Konsumsi periode tahun 2016, edisi: 01/konsumsi/03/2017. Direktorat Jenderal Peternakan dan Kesehatan Hewan (PKH). Kementerian Pertanian. Diakses $\begin{array}{llll}\text { pada } & 12 & \text { Juli } & 2018 .\end{array}$ http://ditjenpkh.pertanian.go.id/userfiles/Fil e/Konsumsi1_Periode_2016.pdf?time $=150$ 1058657531.

Anonimous. 2018. Hasil penelitian MUI, 8 dari 10 sampel ayam proses sembelihnya tidak sah. Lingkar Jatim. Diakses 12 Juli 2018. https://lingkarjatim.com/madura/bangkalan/ hasil-penelitian-mui-8-dari-10-sampelayam-proses-sembelihnya-tidak-sah/

Apriyantono A, Hermanianto J, dan Wahid N. 2007. Pedoman produksi pangan halal. Khairul Bayam Press. Jakarta.

Ardianti Y. 2015. Presentase biaya bahan baku, biaya tenaga kerja, biaya overhead pabrik terhadap harga pokok produksi pada PT Indohama fish tahun 2014. Jurnal Pendidikan Ekonomi Undiksha. 5(1): 1-10.

Badan Standar Nasional. 1999. Standar Nasional Indonesia (SNI) 01-6160-1999. Standar rumah potong unggas. Jakarta. Badan Standar Nasional.

Badan Standar Nasional. 2009. Standar Nasional Indonesia (SNI)3924:2009. Mutu karkas dan daging ayam. Jakarta. Badan Standar Nasional.

Brealey MM. 2007. Dasar-dasar Manajemen Keuangan Perusahaan. Jakarta: Erlangga.

Delfita R. 2013. Evaluasi teknik pemotongan ayam ditinjau dari kehalalan dan keamanan pangan di kabupaten Tanah Datar. Jurnal Saintek. 5(1): 78-87.

Fauziyah SU, Seminar KB, Hermadi I, Suyatma NE. 2017. Sistem pendukung keputusan penyedia dokumen dalam pengajuan sertifikasi halal menurut LPPOM-MUI. Jurnal Teknologi Industri Pertanian. 27(3): 261-270.

Fuseini A, Steve B, Wotton, Phil JH, Toby GK. 2016. The perception and acceptability of preslaughter and post-slaughter stunning for halal production: The views of UK Islamic scholars and halal consumers. Meat Science. 1740 (16): 30315-1.

Gregory NG, von Wenzlawowicz M, Alam RM, Anil HM, Yesildere T, Silva-Fletcher A. 2008. False aneurysms in carotid arteries of cattle and water buffalo during shechita and halal slaughter. Meat Science. 79(2): 285-288.

Gregory. 2007. Animal Welfare And Meat Science. CABI Publishing Wallingford. UK.213-226.

Gumilar J dan Pratama A. 2018. Produksi dan karakteristik gelatin halal berbahan dasar usus ayam. Jurnal Teknologi Industri Pertanian. 28(1): 75-81.

Halkin A, Vasyl S, Evgen K, Kateryna V. Viktor D. 2017. Invest approach to the transportation services cost formation. Proc Eng. 178(1): 435-442.

Jeon Y W, Jong W K, Youang MY, Dong H L. 2013. Unit mass estimation and characterization of litter generated in the broiler house and slaughterhouse. International Biodeterior. Biodegrad. 85(1): 592-597.

Keputusan Menteri Tenaga Kerja dan Transmigrasi RI No 196 Tahun 2014 tentang Penetapan standar kompetensi kerja nasional Indonesia kategori pertanian, kehutanan dan perikanan golongan pokok jasa penunjang peternakan bidang penyembelihan hewan halal.

Kirton AH, Frazerhurst LF, Woods EG, Chystal BB. 1981. The effect of electrical stunning method and cardiac arrest on bleeding efficiency, residual blood, and splash in lambs. Meat Science. 5(1): 347-353.

Kondoy IM, Ventje I, dan Winston P. 2015. Penerapan cost plus pricing dalam keputusan penetapan harga jual untuk pesanan khusus pada UD. Dewa Bakery Manado. Jurnal Berkala Ilmiah Efisiensi. 15(3): 1-11.

Kotler dan Keller. 2009. Manajemen Pemesaran Jilid 1. Erlangga. Jakarta.

LPPOM MUI. 2012. Pedoman pemenuhan kriteria sistem jaminan halal di rumah potong hewan (HAS 23103). Jakarta: LPPOM MUI.

Mahendra R. 2010. Pengaruh jumlah industri dan kapasitas produksi terhadap penyerapan tenaga kerja di Kota Blitar. Universitas Brawijaya. Malang.

Majelis Ulama Indonesia (MUI). 2009. Fatwa MUI No 12 Tahun 2009 tentang penyembelihan halal. MUI.

Malaysian Standard MS1500-2004. 2004. Halal Food Production, Preparation, Handling And Storage-General Guideline (First Version). Department of Standards Malaysia. 1-14.

Malaysian Standard MS1500-2009. 2009. Halal Food Production, Preparation, Handling, 
And Storage-General Guideline. Department of Standards Malaysia. 1-13.

Nakyinsige K, Che Man YB, Aghwan ZA, Zulkifli I, Goh YM, Bakar FA, Al-Kahtani HA, Sazili AQ. 2013. Stunning and animal welfare from Islamic and scientific perspectives. Meat Science. 95: 352-361.

Riszky TI dan Harmami. 2015. Pengaruh suhu terhadap kualitas coating (pelapisan) stainless steel tipe 304 dengan kitosan secara elektroforesis. Jurnal Sains dan Seni ITS. 4(1): 2337-3520.

Rony H dan Etwin F. 2017. Analisis model kehalalan proses potong ayam di rumah potong ayam di Samarinda. SNITT-Politeknik Negeri Balikpapan. 1(1): 19-25.

Setiadi P, David PES, dan Treesje R. 2014. Perhitungan harga pokok produksi dalam penentuan harga jual pada CV. Minahasa Mantap Perkasa. Jurnal Berkala Ilmiah Efisiensi. 14(2): 70-82.

Shahdan I A, Regenstein JM, Shahabuddin ASM, Rahman MT. 2016. Developing control points for halal slaughtering of poultry. Poult. Science. 95(7): 1680-1692.
Shahdan I A, Regenstein JM, Rahman MT. 2017. Critical limits for the control points for halal poultry slaughter. Poult. Science. 96(7): 1970-1981. http://dx.doi.org/10.3382/ps/pew427

Singgih ML dan Kariana. 2008. Peningkatan produksi dan kinerja lingkungan dengan pendekatan green productivity pada rumah pemotongan ayam XX. Jurnal Tekling Purifikasi. 9(2): 110.

Surat Keputusan Menteri Pertanian No. 306/KPTS/TN.330/4/1994 tentang pemotongan unggas dan penanganan daging unggas serta hasil ikutannya.

Tieman M, Maznah C, Ghozali, Jack GA. 2013. Consumer perception on halal meat logistic. Br. Food Journal. 115(8): 1112-1129.

Zivotofsky AZ dan Strous RD. 2012. A perspective on the electrical stunning of animals: Are there lessons to be learned from human electro-convulsive therapy (ECT)?. Meat Science. 90:956-961. 